\section{Sondervertreterversammlung der KBV für neuen EBM}

Grundlegende oder schrittweise Reform des EBM? Darüber soll eine Sondervertreterversammlung der KBV am 26. April beraten, kündigte KBV-Vorsitzender Dr. Andreas Köhler am 2. März vor der internen Arbeitssitzung der KBV-Vertreter in Berlin an. Dabei soll eine Reihe von Grundsatzfragen geklärt werden: Soll das Prinzip differenzierter Pauschalen und ergänzender Einzelleistungen beibehalten werden? Beantwortet werden muss die Frage, wie das Verhältnis von EBM und regionalen Fördermaßnahmen ausgestaltet wird. Entscheidungen müssen auch zu den Modalitäten der Honorartrennung zwischen Haus- und Fachärzten getroffen werden. Ferner will die KBV erreichen, dass im Labor Leistungsausweitungen und Probentourismus eingedämmt werden. Im Arbeitskreis 4 war der Vorschlag, einen Vergütungstopf auf Bundesebene zu schaffen, am 20. Februar abgelehnt worden.

\section{Nationaler Krebsplan soll wiederbelebt werden}

Nach Plänen des BMG soll der 2008 gestartete "Nationale Krebsplan" nun mit Leben erfüllt werden. So soll der Gemeinsame Bundesausschuss die Voraussetzungen dafür schaffen, dass - analog zum Mammografie-Screening - auch für die Früherkennungsprogramme auf Gebärmutterhalsund Darmkrebs Einladungssysteme installiert werden. Insbesondere bei der Darmkrebsfrüherkennung ist die Inanspruchnahme der Untersuchungen seit Jahren trotz intensiver Werbung rückläufig. Einen neuen Anlauf will das BMG für die Errichtung eines bundesweiten Krebsregisters schaffen, dessen Realisierung aber von den Bundesländern abhängig ist. Die Ländergesundheitsministerkonferenz soll sich damit im Juli befassen.

\section{Bundesrat lehnt Arzneiinformation von Herstellern ab}

Der Bundesrat sieht keinen Bedarf dafür, dass Arzneimittelhersteller objektive und behördlich genehmigte Informationen wie beispielsweise den Beipackzettel für verschreibungspflichtige Arzneimittel, direkt dem Publikum zur Verfügung stellen können. Diese Informationserweiterung ist Teil der Novelle des Arzneimittelgesetzes, mit der europäisches Arzneimittelrecht umgesetzt werden soll. Der Bundesrat argumentiert, die Vorlage der EU-Kommission sei nicht geeignet, Patienten vor versteckter Werbung zu schützen.

\title{
KV-Vorstände erhielten 2011 teils kräftige Gehaltszuschläge
}

Die Vorsitzenden und Vorstände der Kassenärztlichen Bundesvereinigung und der Kassenärztlichen Vereinigungen haben im vergangenen Jahr teils erhebliche Gehaltserhöhungen erzielt. Spitzenreiter ist KBV-Chef Dr. Andreas Köhler mit $350.000 €$ und einem Plus von $35 \%$. Das hält das Bundesministerium für Gesundheit nun nicht mehr für angemessen.

$E^{\text {in }}$ ine Entscheidung zu den Vorstandsgehältern der Kassenärztlichen Bundesvereinigung (KBV) verzögert sich. Die $\mathrm{KBV}$ will in dieser Frage mit einem von ihr selbst in Auftrag gegebenen Gutachten Klarheit schaffen. „Daher haben wir das Ministerium um eine Fristverlängerung gebeten“, so der Vorsitzende der KBVVertreterversammlung, Hans-Jochen Weidhaas, „und auch erhalten“. Ursprünglich hatte das Bundesministerium für Gesundheit (BMG) eine Frist zum 9. März gesetzt, die Vorstandsgehälter „an den Grundsätzen der Sparsamkeit und Wirtschaftlichkeit" auszurichten.

Das Gehalt von Dr. Andreas Köhler, Chef der KBV, wurde im letzten Jahr um 90.000 auf $350.000 €$ erhöht, das seines damaligen Vize Dr. Carl-Heinz Müller um 40.000 auf $300.000 €$ im Jahr. Die Zuwächse von $35 \%$ und $15 \%$ hatten unter einigen Delegierten der Vertreterversammlung für Unmut gesorgt. Anfang des Jahres hatte sich Gesundheitsminister Daniel Bahr (FDP) in die Diskussion eingeschaltet und eine Vergütung verlangt, die sich an den Gehältern der Vorstandsvorsitzenden großer Krankenkassen oder ihrer Verbände orientiert. Aus Sicht der KBV ist es allerdings Sache der Selbstverwaltung, die Höhe der Vorstandsgehälter festzulegen.

\section{Hier wie da keine „Sparsamkeit und Wirtschaftlichkeit" ...}

Einige KV-Vorstände verdienen deutlich mehr als im Vorjahr (Abbildung 1). Darunter zum Beispiel die Vorstände der KV Hamburg: Sie erhielten im vergangenen Jahr 240.000 € (2010: 192.000 € und $186.000 €)$. In Sachsen stiegen die Gehälter von $195.000 € \mathrm{im}$ Jahr 2010 auf 240.000 € im Jahr 2011. Am bescheidendsten sind die beiden Vorstände in Baden-Württemberg mit $170.000 €$. Dienstwagen, Fahrkosten und Leistungen für die Altersvorsorge oder die Erlaubnis,

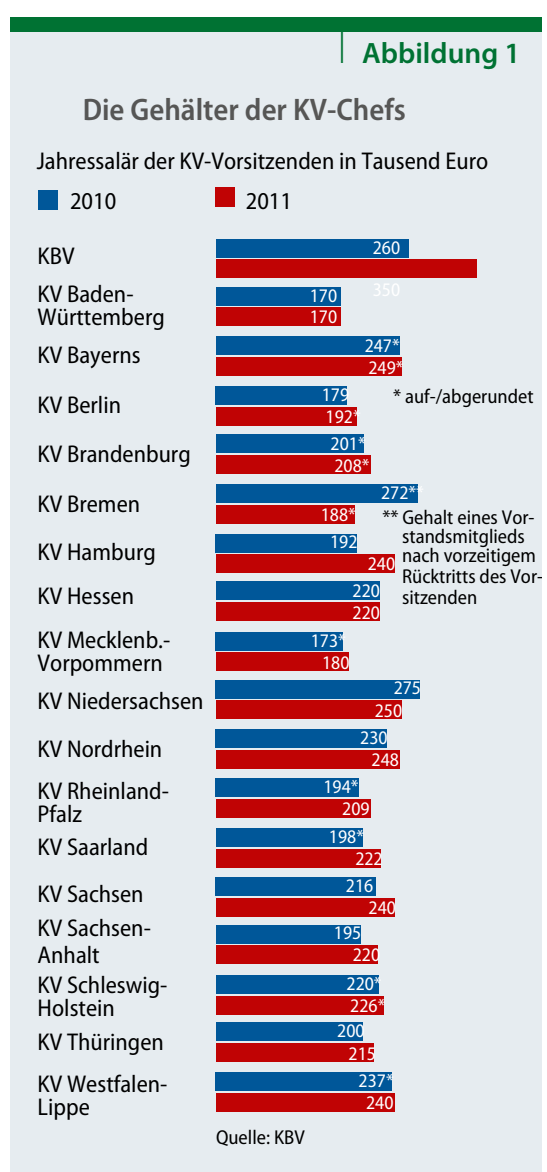

weiter in der Praxis zu arbeiten, sind nicht darin eingerechnet.

\section{... und obendrein Verdacht auf Untreue}

Um die Gehälter der KV Berlin gab es in den vergangenen Wochen viel Unmut. Gegen die drei Vorstände ermittelt nun der Staatsanwalt wegen Verdachts auf Untreue. Die Ermittlungen stehen im $\mathrm{Zu}$ sammenhang mit den Zahlungen von $183.000 €$ an jedes Vorstandsmitglied. Dabei ist das Übergangsgeld, das bei Ausscheiden ausgezahlt werden soll, in eine Prämie umgewandelt worden. sun 